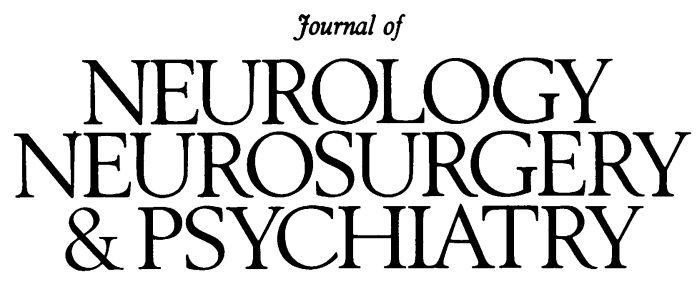

Editorial

\title{
The modern management of Parkinson's disease
}

For the last two decades the medical management of Parkinson's disease (IPD) has been based largely on the use of oral preparations containing levodopa. This period has been more than ample to witness the continuing progression of the underlying disease, and the myriad complications of the long-term levodopa syndrome. Recently, the medical approach has been expanded to incorporate three distinct, but inter-related, arms. First, the possibility that certain treatments might prevent, retard or halt the underlying pathological process. Second, the ability of symptomatic treatment using new drugs, or old drugs with new strategies or delivery systems, to limit the appearance, or lessen the impact, of response fluctuations. Finally, the prospect of restorative treatment using cell implants. This editorial will concern itself with the first two aspects.

The cause of IPD is unknown. However, a clinically identical syndrome (although pathologically lacking classical Lewy bodies) can be induced in humans, and a similar syndrome in other primates, by the protoxin MPTP. Pretreatment with MAO B inhibitors such as selegiline (deprenyl) prevents MPTP-induced parkinsonism in primates ${ }^{1}$ by blocking its conversion in glia or nondopaminergic neurons through the intermediate MPDP ${ }^{+}$ to the toxic moiety $\mathrm{MPP}^{+}$. Dopamine reuptake blockers such as mazindol, nomifensine and benztropine can also protect by inhibiting the uptake of $\mathrm{MPP}^{+}$into dopaminergic neurons. Once within these cells, $\mathrm{MPP}^{+}$is actively accumulated in mitochondria, where it disrupts energy metabolism somewhere between NADH dehydrogenase and coenzyme $Q 10 .^{2} \mathrm{~A}$ redox reaction between $\mathrm{MPDP}^{+}$and $\mathrm{MPP}^{+}$, also blocked by selegiline, may also generate free radicals through the formation of superoxide. ${ }^{3}$

In IPD substantia nigra, recent studies have demonstrated impaired function of complex 1 of the mitochondrial respiratory chain. ${ }^{4}$ In this structure, there is also evidence of an increase in total iron concentration (in the absence of a "neutralising" increase in ferritin) $)^{5}$ and of enhanced lipid peroxidation, ${ }^{6}$ which could be respectively a mediator and a result of free radical attack. The onward metabolism of dopamine itself may also increase oxidative stress. Thus, regardless of whatever initiates the process of nigrostriatal neuronal death, the increased dopamine turnover of surviving cells, and its further acceleration when exogenous levodopa is administered, might cause these neurons to "self-destruct". The use of an MAO B inhibitor, or of a direct dopamine agonist which would diminish presynaptic dopamine turnover, could theoretically limit this process. For example in haloperidol-treated rats selegiline suppresses the rise in glutathione disulfide which occurs as a result of increased dopamine turnover. ${ }^{7}$

Accepting all the uncertainty of the quantum leaps from MPTP parkinsonism to IPD, and from rats through lower primates to humans, the stage is therefore set for studies of the disease-modifying potential of MAO B inhibition, and of anti-oxidant therapies such as alpha-tocopherol (vitamin $\mathrm{E}$ ).

\section{Selegiline}

Selegiline was developed in 1964, its MAO B-blocking activity was discovered in $1972,{ }^{8}$ and a possible symptomatic effect by potentiating levodopa suggested in 1975. ${ }^{9}$ The drug appears to enhance longevity in rats, ${ }^{10}$ and in 1985, using data collected up to August 1983, Birkmayer et $a l^{11}$ published the results of an open, uncontrolled, retrospective study claiming increased life expectancy in 564 patients receiving Madopar plus selegiline, compared to 377 patients treated with Madopar alone. This study was completed before anything was known of the ability of selegiline to protect against MPTP toxicity in primates. Of the many confounding variables, the significantly higher mean dose of Madopar in the selegiline group was particularly unsettling.

Selegiline does not usually exert a significant symptomatic effect when given alone to patients with Parkinson's disease. However, such monotherapy has only been used in a few patients, and at least one open study ${ }^{12}$ has demonstrated significant improvement on the Webster score at both three and six months in a group of 30 patients. The metabolism of selegiline produces small amounts of amphetamine and methamphetamine and, whether due to this or other effects, the drug has been claimed to be "the best drive-boosting antidepressant available", ${ }^{13}$ although many would question the evidence for this.

The results of two randomised double-blind prospective studies of selegiline versus placebo in otherwise untreated subjects with early PD have recently been published. ${ }^{14} 15$ The end-point for individual patients in each study was when, in the judgement of the investigator, a subject reached a level of functional disability sufficient to warrant the initiation of levodopa therapy, or when the subjects had completed three ${ }^{1416}$ years of treatment without needing levodopa. In both studies, a washout period of one month was observed after end-point and before starting levodopa in the hope that any "symptomatic" effect of selegiline might thereby be detected (although PET studies ${ }^{17}$ have shown that partial inhibition of MAO B due to selegiline is still present at least three weeks after the last dose). As well 
as semi-objective PD rating scales, scales for depression were also administered.

The results of each study were broadly similar: both used $10 \mathrm{mg}$ selegiline daily. The California study ${ }^{14}$ did not detect significant overall clinical improvement on starting selegiline treatment. The DATATOP study ${ }^{15}$ found statistically significant short-term ("wash-in") benefits that favoured the selegiline-treated patients, but the changes were slight and possibly of no clinical consequence. Moreover, they could not adequately explain a long-term reduction in the rate of reaching end-point (see below). Neither study has so far detected significant clinical deterioration during the washout period. Nor, with the rating scales used, was any anti-depressant effect of selegiline detected which might have influenced the patients' willingness to soldier on without levodopa. Although the use of multiple analyses always introduces the possibility of freak individually significant results, the effect was fairly consistent across all measures of disability. The smaller California study ${ }^{14}$ (27 patients in each group at entry, 22 in each group at end point) found that the average time until levodopa was needed was $312 \cdot 1$ days for placebo, and 548.9 days for selegiline. In the much larger DATATOP study, ${ }^{15}$ after 12 months of follow up, of 399 subjects assigned to selegiline, alone or with tocopherol $2000 \mathrm{iu} /$ day, and 401 assigned to tocopherol or placebo, only 97 of the first group reached end-point, compared with 176 of the second group $\left(p<10^{-8}\right)$. This study remains on-going, the early disclosure of the above results arising because a predetermined level of significance $(p<0.001)$ was reached only for the deprenyl versus no deprenyl comparisons. The results of the comparisons between tocopherol and placebo, having not yet reached this predetermined level of significance, must await completion of the study, scheduled for autumn 1990. More extensive data on the effect of selegiline washout at endpoint are still being generated and yet to be analysed. The authors of both studies, particularly DATATOP, have been cautious in wording their conclusions: Tetrud and Langston! ${ }^{14}$ stated: "Disease progression, as monitored by five different assessment scales, was slowed . . Therefore early deprenyl therapy delays the requirement for antiparkinsonian medication, possibly by slowing progression of the disease". The Parkinson study group ${ }^{15}$ concluded that "the use of deprenyl . . . delays the onset of disability associated with early, otherwise untreated cases of Parkinson's disease ... Although the primary effect of treatment was unequivocal, the mechanism (symptomatic, protective, or both) of the effect is unclear".

How will the results of these studies affect everyday prescribing and ongoing clinical research? There will be pressure from various sources to start lifelong treatment with selegiline in every patient with parkinsonism as soon as the first symptoms appear. A more extreme view, given the suspected 20 to 30 year presymptomatic period, would be to treat the entire population from their 50th birthday. An intermediate course would be to find some method of presymptomatic diagnosis in order to target those who might benefit. Yet we still do not understand the mechanisms underlying these important observations. Nor do we know (other than from the study of Birkmayer et $a^{11}$ ) whether the use of selegiline later in the disease, when levodopa has been started, influences the progression of underlying disability. Certainly, the drug has been used long enough in Europe to recognise that selegiline does not halt the progression of the disease or the development of fluctuations and dyskinesias. It would be a pity if the preliminary results from DATATOP were to cause such enquiry, like a nigrostriatal neuron, to self-destruct, but it will now prove difficult not to accede to the request of patients at any stage of the disease to be prescribed selegiline.
Early combination therapy using oral dopamine agonists

Dopamine agonists might also theoretically slow nigral cell loss by diminishing oxidative stress, firstly by negative feedback and secondly by a levodopa-sparing effect, but this remains entirely speculative. What is emerging, however, is clinical evidence to suggest that early treatment with a dopamine agonist combined with levodopa may, through whatever mechanism, prevent or delay the development of fluctuations and dyskinesias. An initial open study ${ }^{18}$ (the unplanned progeny of a study of bromocriptine monotherapy) was subject to several criticisms, including the use of non-contemporaneous controls. However, a subsequent prospective study $^{19}$ comparing the early combination of levodopa with lisuride versus levodopa alone again showed that, for a similar degree of clinical benefit, the early combination group experienced significantly less fluctuations and dyskinesias after four years. To what extent this observation is the result of the theoretical factors considered above, or to more sustained dopamine receptor stimulation or a $D_{1} / D_{2}$ profile different from levodopa alone is unknown. Such an approach to early treatment clearly merits further study.

\section{Management of established fluctuations}

Once fluctuations and dyskinesias are established, traditional approaches such as dose fractionation, adding oral agonists with a different time profile, and rescheduling protein intake are only partly successful. Since the fluctuations are largely related to peaks and troughs of plasma levodopa levels (and hence striatal dopamine levels), this variation can be reduced (in increasing order of success both in plasma levels and clinical response) by controlled or sustained release oral formulations, or the continuous administration of levodopa solution by intragastric, intraduodenal or intravenous infusion. The parenteral route has the advantage of by-passing the vagaries of gastro-intestinal transit and absorption, but the large volumes of solution needed are not practicable (although the use of the highly soluble methyl ester of levodopa ${ }^{20}$ may convey an advantage). Hence the search for a highly soluble dopamine agonist suitable for parenteral use. Continuous subcutaneous infusions of lisuride, a $\mathrm{D}_{2}$ receptor agonist, were tried first. However, in advanced patients it often caused unacceptable psychiatric side-effects. Nor were single intravenous injections of lisuride entirely reliable in reversing established off periods..1

\section{Apomorphine}

This brought researchers full circle to re-explore the use of the combined $\mathrm{D}_{1}-\mathrm{D}_{2}$ agonist apomorphine, the injection of which could, as Schwab et a $l^{2}$ demonstrated in 1951, give short-lived but marked improvement of parkinsonism. Unfortunately, its use was commonly associated with nausea, vomiting, hypotension and drowsiness, and the oral preparation caused reversible azotaemia. However, Corsini et al in $1979^{23}$ showed that the peripheral side-effects could be controlled by oral domperidone. Taking leaves from the diabetologists' book the group at University College/Middlesex Hospital in London ${ }^{24}$ (and others ${ }^{25-28}$ ) have since convincingly demonstrated that repeated single subcutaneous injections of apomorphine using a Penject system, and suitably targeted to be given during, or in anticipation of, off periods, significantly reduces daily off time in fluctuating patients. Benefit usually occurs within 5-15 minutes, and lasts 40-90 minutes. More complex cases have been given continuous day-time subcutaneous infusions of apomorphine using a simple battery-operated syringe-driver pump.

The article in this issue ${ }^{29}$ expands their earlier experience. Of 57 patients accepted for treatment, six failed to gain a worthwhile response. In 30 patients who received 2-18 (mean $4 \cdot 8$ ) injections/day, each of $0 \cdot 2$ to 5 (mean $2 \cdot 2$ ) 
mg, mean daily off time fell from 6.9 to 2.9 hours. In 21 patients receiving continuous daytime infusion, usually at 2 to $4 \mathrm{mg} / \mathrm{hr}$, with an additional mean of 9.5 "on demand" boluses of mean $2.4 \mathrm{mg}$, mean hours off per day fell from 9.9 to 4.5 , and a significant reduction in daily levodopa dosage was possible in most subjects. The effect on dyskinesias was variable: most patients with diphasic dyskinesias fared badly, and even with peak dose chorea it was not always possible to achieve worthwhile improvement.

Another benefit of acute boluses of apomorphine is prompt relief from a number of unpleasant positive off period phenomena, in particular distressing attacks of painful, fixed, off period dystonia. ${ }^{25}$ The principal unwanted side effect was the development of tender nodules ("the Quatermass effect") at the abdominal injection sites, despite frequent re-siting of the needle. Tolerance to peripheral dopaminergic side-effects developed in many subjects, who were then able to reduce or stop domperidone. Neuropsychiatric problems arose in only four subjects, and in two of these they were reversible. On the basis of these and other results, the use of subcutaneous apomorphine represents a major advance in the management of patients with IPD who, despite using all other measures at our disposal, remain disabled by their response fluctuations. Moreover, since its symptomatic effect is considerably greater than even the best results claimed for transplants ${ }^{30}$ outside Mexico, it should probably be offered first to any patient being considered as a candidate for grafting experiments.

However, our enthusiasm should be tempered with some caution. Subjects whose "best response" to levodopa is poor are similarly unlikely to benefit from apomorphine; those with a diphasic response usually fare badly, just as they do with overlapping or slow release doses of levodopa; a certain measure of dexterity on the part of patient or spouse is needed to charge the apparatus and place the injection, as is intelligence and experience on the part of patient and doctor in knowing when and how much to give. A large treatment programme also ties up scarce medical resources so that every department treating Parkinson's disease should now be offering this therapy to selected patients. Moreover, such a programme underscores the need for a new breed of nurse practitioners who understand the disease and its treatment.

\section{Other approaches}

Other new therapies for Parkinson's disease have also been investigated, but with a high attrition rate due to animal or human toxicity. In recent years both lergotrile and mesulergine have fallen by the wayside. PHNO, a highly soluble non-ergot $\mathrm{D}_{2}$ agonist also active via the transdermal route has recently been withdrawn, as has the $\mathrm{D}_{1}$ agonist CY 208-243.

Finally, the difficulty of treating established response fluctuations has given fresh impetus to exploring early treatment regimes whose use may be associated with fewer long-term problems. In this context, treatments initially designed to manage fluctuations may actually be more beneficial if applied early in the course of the disease. It should really surprise no one that a brain flooded and starved of dopamine three times a day should sooner or later protest by producing response fluctuations. Thus sustained or controlled release oral levodopa or agonist preparations, or the use of transdermal or other continuous parenteral delivery systems, may meet with more success when applied early rather than late.

Institute of Neurology,

NIALL QUINN

Queen Square, London.

1 Heikkila RE, Manzino L, Cabbat FS, Duvoisin RC. Protection against the dopaminergic toxicity of 1-methyl-4-phenyl-1,2,5,6-tetrahydropyridin by monoamine oxidase inhibitors. Nature 1984;311:467-9.

2 Singer TP, Castagnoli N, Ramsay RR, Trevor AJ. Biochemical events in the development of parkinsonism induced by 1 -methyl-4-phenyl-1,2,3,6tetrahydropyridine. $J$ Neurochem 1987;49:1-8.

3 Rosetti ZL, Sotgiu A, Sharp D, Hadjiconstantinou M, Neff NH. 1-methyl4-phenyl-1,2,3,6-tetrahydropyridine (MPTP) and free radicals in vitro. Biochem Pharmacol 1988;37:4573-4.

4 Schapira AHV, Cooper JM, Dexter D, Jenner P, Clark JB, Marsden CD. Mitochondrial complex 1 deficiency in Parkinson's disease. Lancet 1989;i:1269.

5 Dexter DT, Wells FR, Lees AJ, Agid F, Agid Y, Jenner P, Marsden CD. Increased nigral iron content and alterations in other metal ions occurring in brain in Parkinson's disease. $J$ Neurochem 1989;52:1830-6.

6 Dexter DT, Carter C, Agid F, et al. Lipid peroxidation as a cause of nigral cell death in Parkinson's disease. Lancet 1986;ii:639-40.

7 Cohen G, Spina MB. Deprenyl suppresses the oxidant stress associated with increased dopamine turnover. Ann Neurol 1989;26:689-90.

8 Youdim MBH, Collins GGS, Sandler M, Jones Bevan AB, Pare CMB Nicholson WJ. Human brain monoamine oxidase, multiple forms and selective inhibitors. Nature 1972;236:225-8.

9 Birkmayer W, Riederer P, Youdim MBH, Linauer W. The potentiation of the antiakinetic effect after L-dopa treatment by an inhibitor of MAO-B, deprenyl. J Neural Transm 1975;36:303-26.

10 Knoll J. R-(--)-deprenyl (selegiline, Movergan) facilitates the activity of the nigrostriatal dopaminergic neuron. J Neural Transm 1987;(suppl)25: 45-66.

11 Birkmayer W, Knoll J, Riederer P, Youdim MBH, Hars V, Marton J. Increased life expectancy resulting from addition of L-deprenyl to Madopar treatment in Parkinson's disease: A longterm study. $J$ Neural Transm 1985;64:113-27.

12 Csanda E, Tárczy M. Selegiline in the early and late phases of Parkinson's disease. J Neural Transm 1987;(suppl)25:105-13.

13 Birkmayer W. Panel discussion. J Neural Transm 1987;(suppl)25:175-94.

14 Tetrud JW, Langston JW. The effect of deprenyl (selegiline) on the natura history of Parkinson's disease. Science 1989;245:519-22.

15 Shoulson I, and the Parkinson Study Group. Effect of deprenyl on the progression of disability in early Parkinson's disease. $N$ Engl J Med progression of disa

16 Shoulson I, and the Parkinson Study Group. DATATOP: A multicentre controlled clinical trial in early Parkinson's disease. Arch Neurol controlled clinica

17 Leenders KL, Aquilonius SM, Fowler JS, et al. Localisation and quantification of monoamine oxidase (MAO B) in brain in healthy volunteers and parkinsonian patients using PET. J Cereb Blood Flow Metab 1987;7:S370.

18 Rinne UK. Early combination of bromocriptine and levodopa in the treatment of Parkinson's disease: a 5-year follow-up. Neurology 1987;37:826-8.

19 Rinne UK. Lisuride, a dopamine agonist in the treatment of early Parkinson's disease. Neurology 1989;39:336-9.

20 Cooper DR, Marrell C, Testa B, et al. L-dopa methyl ester-A candidate for chronic systemic delivery of L-dopa in Parkinson's disease. Clin Neurochronic systemic deliver

21 Hardie RJ, Lees AJ, Stern GM. On-off fluctuations in Parkinson's disease: clinical and neuropharmacological study. Brain 1984;107:487-506.

22 Schwab RS, Amador LV, Lettvin JY. Apomorphine in Parkinson's disease. Trans Amer Neurol Assoc 1951;76:251-3.

23 Corsini GU, Del Zompo M, Gessa GL, Mangoni A. Therapeutic efficacy of apomorphine combined with an extracerebral inhibitor of dopamine receptors in Parkinson's disease. Lancet 1979;i:954-6.

24 Stibe CMH, Kempster PA, Lees AJ, Stern GM. Subcutaneou apomorphine in parkinsonian on-off oscillations. Lancet 1988;i:403-6.

25 Poewe W, Kleedorfer B, Gerstenbrand F, Oertel W. Subcutaneous apomorphine in Parkinson's disease. Lancet 1988;i:943.

26 Chaudhuri KR, Critchley P, Abbott RJ, Pye IF, Millac PAH. Subcutaneous apomorphine for on-off oscillations in Parkinson's disease. Lancet 1988;ii: 1260 .

27 Pollak P, Champay AS, Hommel M, Perret JE, Benabid AL. Subcutaneous apomorphine in Parkinson's disease. J Neurol Neurosurg Psychiatry 1989;52:544.

28 Ruggieri S, Stocchi F, Carta A, Agnoli A. Side-effects of subcutaneous apomorphine in Parkinson's disease. Lancet 1989;i:566.

29 Frankel JP, Lees AJ, Kempster PA, Stern GM. Subcutaneous apomorphine in the treatment of Parkinson's disease. J Neurol Neurosurg Psychiatry 1990;53:96-101.

30 Goetz CG, Olanow CW, Koller WC, et al. Multicentre study of autologous adrenal medullary transplantation to the corpus striatum in patients with advanced Parkinson's disease. N Engl J Med 1989;320:337-41. 